\title{
Case Study on Improving Quality Management of W Company's New Product Development Project
}

\author{
Jiangping Wan ${ }^{1,2}$, Ming Zeng ${ }^{1}$ \\ ${ }^{1}$ School of Business Administration, South China University of Technology, Guangzhou, China \\ ${ }^{2}$ Institute of Emerging Industrialization Development, South China University of Technology, Guangzhou, China \\ Email: scutbmwjp@126.com,zm656690@qq.com
}

Received April 23, 2013; revised May 23, 2013; accepted June 1, 2013

Copyright (C) 2013 Jiangping Wan, Ming Zeng. This is an open access article distributed under the Creative Commons Attribution License, which permits unrestricted use, distribution, and reproduction in any medium, provided the original work is properly cited.

\begin{abstract}
Case study on improving quality management of W company's new product development project includes the analysis of the current situation within the quality management of W company's new product development project (current situation and identify existing problems), improvement study (analysis the cause of existing problems and design the improvement scheme) and implementation. Through monitoring the implementation process, we have an evaluation analysis for the implementation results. The purpose of this study is to improve quality management of new product development project.
\end{abstract}

Keywords: New Product Development; Quality Management; Quality Improvement; Analytic Hierarchy Process; Cause; Effect Diagram; Case Study

\section{Introduction}

The definition given by ISO9001:2000 is "Quality is the degree to which a series of inherent characteristics meet the requirements" [1]. Nowadays, the quality not only refers to the specific product quality, but also more emphasizes on product performance to achieve customers' satisfaction. The core of TQM (Total Quality Management) is "Three-Full-Management", namely comprehensive quality management, the whole process quality management, quality management participated by all the staff [2]. At the same time, 6 Sigma management technology, MSA (Measurement System Analysis) technology, and other methodologies have been introduced to the management, these methodologies provide a systematic solution to the quality management of new product development project [3].

W Company, which has conducted business over twenty years, is located in Chinese mainland, Hong Kong, Taiwan, the United States and other countries and regions. W company takes "innovative technology and leading products" as the principle, and promises the integrity, compatibility, security, stability of the system for two reasons. On one hand, it relies on the product technology,

\footnotetext{
*This research was supported by Key Project of Guangdong Province Education Office (06JDXM63002), NSF of China (70471091), and QualiPSo (IST-FP6-IP-034763).
}

quality of service, and the advantages in research, development, production sales and service. On the other hand, it is attributed to the cooperation with well-known universities and research institutes, as well as the international technology change. This makes the win-win relationship between the company and customers. The success of W company makes contribution to its strong improving solution to the project quality management of the new product development.

This paper is structured in the following: Section 2 is literature review, including the theory of project quality management, the theory of the quality management of new product development project, and the introduction of tools and methods in the quality management of new product development project. Section 3 analyzes the current situation of the quality management of new product development project. Section 4 is the improving study to the quality management of new product development project. Section 5 describes the implementation process and effect analysis of the improving scheme. Section 6 is the conclusion.

\section{Literature Review}

The definition of the project quality in project quality management includes both the quality of project process and the quality of project product, which aims to empha- 
size the customers' satisfaction. Project quality management finishes related activities mainly with quality plan, quality assurance, quality improvement and other approaches [4]. Management activities include various activities related to all the management functions, which can decide the strategies, responsibilities and objectives of quality work [5] (Figure 1).

The quality management of new product development project is based on project quality process management. And the establishment of quality plan and quality target, implementation of quality assurance plan, quality improvement scheme, quality measurement and deviation analyses of the new product development project constitute the quality management activities of new product development project [6]. These four parts accord with the PDCA cycle, which keep cycling to ensure the product development quality (Figure 2). Quality targets of the new product development project are the purpose of the constant pursuit for quality of product development project. The quality plans of new product development project are the specific implementation of the quality targets of the new product development project. And quality controls of new product development project mean a variety of methods and measures taken for the completion of the quality targets, which are devoted to finishing the quality management targets of new product development project. The quality assurance of new product development project not only includes the internal quality assurance of the project, but the external quality assurance provided for customers and other stakeholders. At the same time, quality improvement of new product development project realize its quality targets by improving process quality, it's a continuous quality activity to improve the efficiency and effectiveness. Furthermore, the quality improvement has six main steps: Ascertain the improving problems, understand current situation, identify the causes, formulate measures and carry out, monitor the implementation process, prevent recurrence and standardize the solution [7].

Cause-and-effect diagram, also known as fishbone diagram, is a method for analyzing cause and effect. This diagram is invented by Kaoru Ishikawa, a Japanese management master, so it is also named Ishikawa diagram. Cause-and-effect diagram can help us identify the basic reasons of the problems and show them with fishbone. As a non-quantitative research tool, Cause-and-effect diagram has been fully applied in industrial production, medical treatment, education and other areas [8].

Analysis hierarchy process, which is called AHP, is a kind of multi-objective decision-making method combining quantitative methods with qualitative methods [9], it is put forward by American scholar A. L. Seaty in 1970s [10]. This method can make the various elements in a complex system layered and organized causing the ele-

\begin{tabular}{|c|c|c|}
\hline \multirow[b]{2}{*}{5} & Project Quality Management & \multirow[b]{2}{*}{7} \\
\hline & 1 & \\
\hline Quality Plan & Quality Assurance & Quality Control \\
\hline $\begin{array}{l}\text { 1. Inputs } \\
\text { 1) Quality strategies } \\
\text { 2) Scope statements } \\
\text { 3) Product introductions } \\
\text { 4) Standards and rules } \\
\text { 5) Output s of other programs } \\
\text { 2. Methods and Skills } \\
\text { 1) Benefit/component } \\
\text { analyses } \\
\text { 2) Basic level standards } \\
\text { 3) Flow charts } \\
\text { 4) Test designs } \\
\text { 3. Outputs } \\
\text { 1) Quality management plans } \\
\text { 2) Operational definitions } \\
\text { 3) Inspection sheets } \\
\text { 4) Inputs of other programs }\end{array}$ & $\begin{array}{l}\text { 1. Inputs } \\
\text { 1) Quality management plans } \\
\text { 2) Quality control test results } \\
\text { 3) Operational definitions } \\
\text { 2. Methods and Skills } \\
\text { 1) Methods and skills of quality } \\
\text { plan } \\
\text { 2) Quality inspections } \\
\text { 3) Flow charts } \\
\text { 4) Test designs } \\
\text { 3. Outputs } \\
\text { 1) Quality improvements }\end{array}$ & $\begin{array}{l}\text { 1. Inputs } \\
\text { 1) Work results } \\
\text { 2) Quality management plans } \\
\text { 3) Operational definitions } \\
\text { 2. Methods and skills } \\
\text { 1) Inspections } \\
\text { 2) Control sheets } \\
\text { 3) Pilot charts } \\
\text { 4) Sample statistics } \\
\text { 5) Flow charts } \\
\text { 6) Trend analyses } \\
\text { 3. Outputs } \\
\text { 1) Quality improvements } \\
\text { 2) Acceptable decisions } \\
\text { 3) Rework } \\
\text { 4) Inspection sheets after } \\
\text { completion } \\
\text { 5) Debugging }\end{array}$ \\
\hline
\end{tabular}

Figure 1. The main flow of project quality management.

\begin{tabular}{|c|c|}
\hline $\begin{array}{c}\text { Quality plans and quality targets of } \\
\text { new product development project }\end{array}$ & $\begin{array}{c}\text { Implementation of quality assurance plan of } \\
\text { new product development project }\end{array}$ \\
\hline $\begin{array}{c}\text { Quality improvement scheme of new } \\
\text { product development project }\end{array}$ & $\begin{array}{c}\text { Quality measurement and deviation analyses } \\
\text { of new product development project }\end{array}$ \\
\hline
\end{tabular}

Figure 2. The PDCA cycle of quality management of new product development project. 
ments in the same layer relatively independent. On this basis, we can quantitatively describe the relative importance for the elements through qualitative judgment [11]. Meanwhile, we can use mathematical theories computing the weight of the elements in the same layer. If there is many layers in AHP model, we should normalize and compute the relative weight in the whole model after confirming the weight of the last layer. The solution layer is under the index layer, therefore, we should get the total score in solution layer by calculating the score for every solution in this layer, which is mathematically computed by scoring for elements in the last layer of the index layer for one solution. We should ascertain the research questions firstly, then establish the structure model which includes target layer, criterion layer and plan layer to form a hierarchical structure with Analytic Hierarchy Process (AHP); and score every element related to current layer and quantify their relative importance to their upper strata element, form quantitive judgment matrix using 1 9 scaling method; judge matrix to see whether it has the consistency condition with the consistency index contained in data, calculate the relative importance coefficient of every layer comparing with the one of upper strata; standardize the weight of each layer relative to the overall goal to get the priority weight, Then do consistency check for every layer from high to low; finally, analyze and summarize.

\section{Analysis of Current Situation within the Quality Management of W Company's New Product Development Project}

\subsection{Requirement of the Quality Management of W Company's New Product Development Project}

The activities of the quality management of W company's new product development project must comply with the company's quality policy, namely "excellent technology, high-quality products, credible and sincere service". Also W company develops a quality policy of reducing noxious substance (HSF quality exemption policy), that can prevent pollution, reduce the cost and be continuous improvement. W company developed a general goal of quality from four aspects: The products' defect rate listed through major design is zero, the system total score for checking should be more than 90 , the site products' failure rate is less than $10 \%$, the customer satisfaction is greater than or equal to $93 \%$.

\subsection{Status of the Quality Management of W Company's New Product Development Project}

The quality management of W company's new product development project uses ISO9001:2000 standard, at the same time, makes a tailoring in terms of the quality management system. 1) W company recognizes the process involved and forms specific files; 2) W company's quality management system can implement and maintain within the internal, and strive to achieve continuous improvement; 3) The managers are in charge of the establishment and maintenance for the organization's quality management system. Departments are responsible for the system implementation and maintenance, keeping continuous improvement for their own department; 4) W company can provide, utilize and effectively manage the required resources needed for quality activities during the new product development process, and ensure the information transfer effectively through a variety of internal meeting; 5) Monitor the customer satisfaction using the internal quality audit; 6) W company develops the corresponding process to control outsourcing process.

\subsection{Problem Identification of the Quality Management of W Company's New Product Development Project}

Through conducting a semi-open examination and discussing with quality control groups of this company, we find out 20 problems existing in the quality management of new product development project: 1) The reliability performance of new products is poor, the repair rate is too high, there are a lot of batch problem, there is a huge gap from the target; 2) The quality of the new product is unable to support the rapid development of business, new product has a lot of problems of concession, the stop line is serious; 3) The performance of purchase quality is poor, the majority of the materials can not achieve the basic goal of quality requirements, they bring great pressure on the processing and assembly process, the result is the quality of new product is unstable; 4) Customer complaints increased obviously, the cost pressure of the service significantly increased; 5) The quality organization can't support all business of W company very well; 6) The roles and responsibilities is not clear within the quality management organization; 7) The organizational structure of IPD (integrated product development) model is preliminary established, IPMT (integrated portfolio management team)/PDT (product development team) organization haven't yet to be further promotion, no more form a mature mode; 8) Quality management activities are not clear, communication and reporting system is not smooth; 9) The process system is not integrate; 10) The evaluation of process system is not perfect; 11) The design standards of new product are not perfect; 12) The standard system of the new product quality is not perfect; 13) The quality target decomposition mechanism is not perfect; 14) The project planning and kickoff phase lack of management; 15) Lack of monitoring and evaluation mechanism for new product project; 16) The management for new pro- 
duct project data is weak; 17) The description for the required ability of post is not clear, the resources are not fully utilized; 18) The support of IT tools for business is not enough; 19) Excellent engineering method and concrete practice are not effective implement within the company; 20) The quality awareness between employees is poor, training is not effective implement.

\section{Improvement Research of Quality Management of W Company's New Product Development Project}

\subsection{The Cause Analysis of the Quality Management of W Company's New Product Development Project}

\subsubsection{The Identified Process for the Cause of Problems}

Based on the Cause and Effect Diagrams of the problems existing in the quality management of W company's new product development project, we reveal 31 causes (Figure 3).

\subsubsection{Cause Cluster Analysis and Weight Design}

1) The process of Cluster Analysis

Through clustering analysis for 31 influencing factor, we get a result as shown in Table 1.

2) The Process of Weight Design

We allocate the weight of key affecting factors with Analytic Hierarchy Process (AHP). The first layer is the target layer, namely the quality management of $\mathrm{W}$ company's new product development. The second layer is the index layer factors.

We get the marking result of 10 experts within W company using the expert scoring method, and then we handle the marking result with Expert-Choice.

In Table 2, A represents the problems existing in the quality management of $\mathrm{W}$ company's new product development project, $B_{1}$ represents "Quality management system of new product development project is not perfect", $B_{2}$ represents "The executive ability of quality management organization is insufficient", $B_{3}$ represents "Process system is not ability of quality management organization is insufficient", $\mathrm{B}_{4}$ represents "Procurement quality control is weak", $\mathrm{B}_{5}$ represents "The values of employees deviate from Business goals", $\mathrm{B}_{6}$ represents "The training scheme for Employees is not reasonable", $\mathrm{B}_{7}$ represents "The enterprise basic resources are not effective utilize". According Table 2, we sort the key affecting factors (Table 3).

\subsection{Improvement Scheme Design for Quality Management of W Company's New Product Development Project}

Basing on the analysis of the 7 key affecting factors, we design a quality management improvement scheme for W company's new product development project.

\subsubsection{Reinforce Construction, Implementation of Process System and Improve Execution of Quality Organization}

First we should strengthen the execution of the process. It requires the support of management, fully authority to IPD. On this basis, the IPD organization is able to effectively carry out the internal and external communication, coordinate various departments involved in the activities of quality management within new product development project, establish an effective communication platform. At the same time, indoctrinate the idea of improving the overall efficiency according to the process to all the staff of W company.

Secondly, promote vigorously the IPMT method in the internal organization during the development process of new product within $\mathrm{W}$ company, improve organization process. As core organization of new product development, IPMT must exist in a cross-functional team form, IPMT organizational structure design is shown in Figure 4.

Finally, according to the existing problem which lacks of assessment mechanism in process system, we should use corresponding statistical analysis tools to analysis the effect of process implementation, which mainly includes the analysis of measuring system (MSA), statistical process control (SPC) technology introduce the defects analysis matrix.

\subsubsection{Complete Quality Management System of New Product Development Project}

First of all, carry out the quality management system of new product development project. Improve the quality of management organization, clarify corresponding assignment of responsibility, empower the corresponding right. So $\mathrm{W}$ company redesign the quality system of new product development, modify the quality organization structure.

RD represents research and development, SM represents sales and marketing, PD represents product development, ES represents engineering services, PE represents process engineering, QM represents quality management, PM represents planning management, PU represents purchasing, $\mathrm{MC}$ represents manufacturing, $\mathrm{CP}$ represents corporation planning, HR represents human resources, SR represents software research, TR represents technical research, IN represents information, VB represents software research, IB represents software research, SC represents supply chain (Figure 5, VB, IB, SC will involve in Table 4).

After ensuring the functional architecture of quality management organization, we should implement the quality management system of new product development pro- 


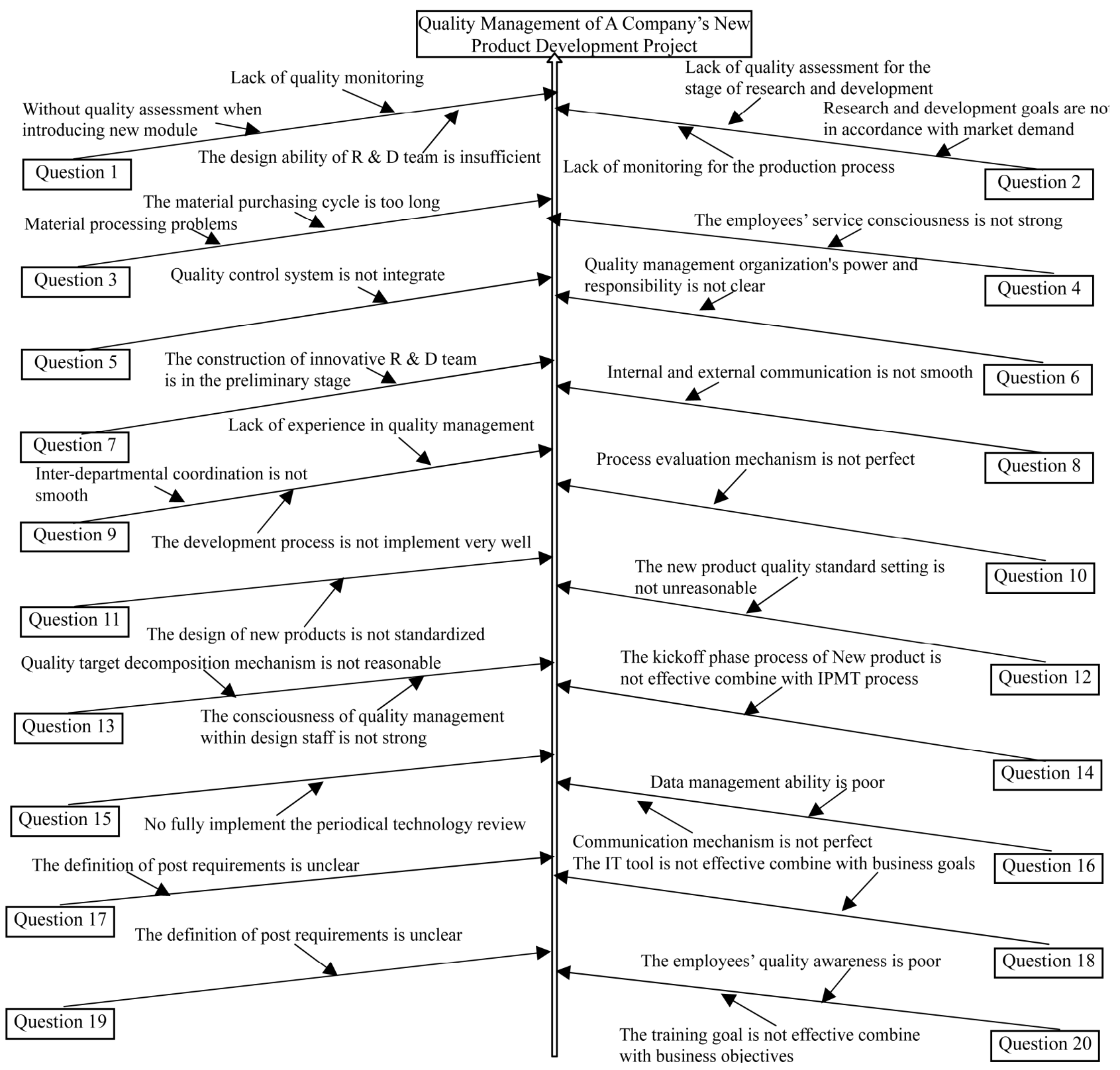

Figure 3. Cause and effect diagram of problems in the quality management of new product development project.

ject into practical work and distribute the different factors involved in quality system to the practical activity of relevant functional departments (Table 4).

Second, establish and improve the technique review of new product development. The technical review of new product development new applies to all activities of $\mathrm{W}$ company's new product development project, has a great support for the new product development project. Detailed technical review ensures that the success of W company in the following activities of new product development, makes $\mathrm{W}$ company walk in the forefront of the industry. The definition involved in new product development project is showed in Table 5 .

\subsubsection{Intensifying Training of Workers to Promote Their Quality Consciousness, and Making a Career Planning for the Staff}

W company passes through the following measures to improve the "employee values deviate from the enterprise target" and "employee training plan is not reasonable": Enhance staff awareness of new product development project quality management and staff training quality consciousness; conduct several training for employees which include management knowledge, professional knowledge (software and hardware), product knowledge, process standards and generic skills ; the training contents are divided into internal training and external training; establish cor- 
Table 1. The result of cause cluster analysis for problems in the quality management of new product development.

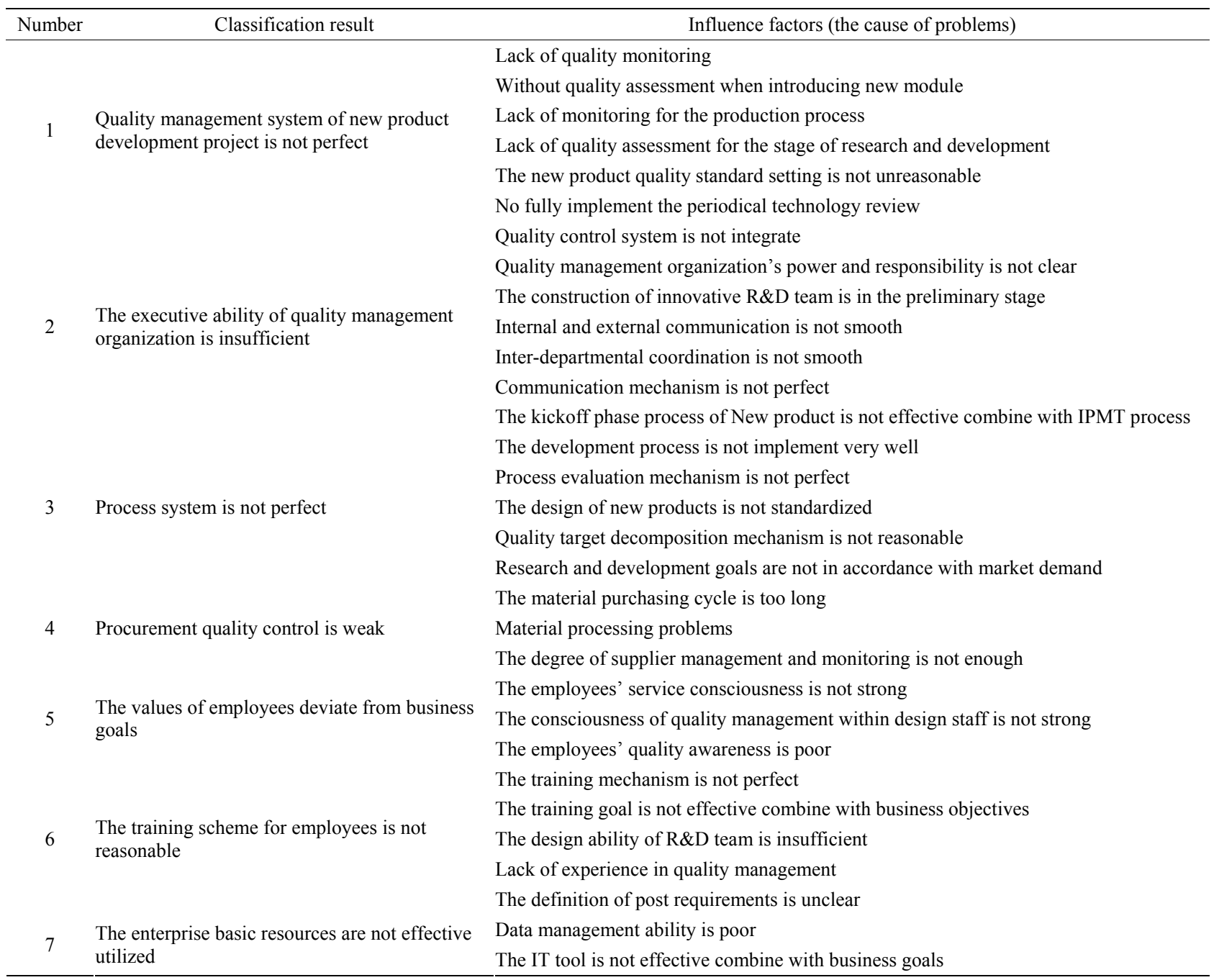

Table 2. AHP calculation result.

\begin{tabular}{|c|c|c|c|c|c|c|c|c|c|}
\hline $\mathrm{A}$ & $\mathrm{B}_{1}$ & $\mathrm{~B}_{2}$ & $\mathrm{~B}_{3}$ & $\mathrm{~B}_{4}$ & $\mathrm{~B}_{5}$ & $\mathrm{~B}_{6}$ & $\mathrm{~B}_{7}$ & $\mathrm{~W}_{\mathrm{i}}$ & Consistency checking \\
\hline $\mathrm{B}_{1}$ & 1 & 2 & $1 / 2$ & 4 & 3 & 2 & 6 & 0.226 & \multirow{7}{*}{ C.R. $=0.03$} \\
\hline $\mathrm{B}_{2}$ & $1 / 2$ & 1 & $1 / 3$ & 3 & 3 & 2 & 5 & 0.168 & \\
\hline $\mathrm{B}_{3}$ & 2 & 3 & 1 & 5 & 3 & 2 & 6 & 0.308 & \\
\hline $\mathrm{B}_{4}$ & $1 / 4$ & $1 / 3$ & $1 / 5$ & 1 & $1 / 2$ & $1 / 3$ & 3 & 0.057 & \\
\hline $\mathrm{B}_{5}$ & $1 / 3$ & $1 / 3$ & $1 / 3$ & 2 & 1 & $1 / 2$ & 3 & 0.082 & \\
\hline $\mathrm{B}_{6}$ & $1 / 2$ & $1 / 2$ & $1 / 2$ & 3 & 2 & 1 & 3 & 0.125 & \\
\hline $\mathrm{B}_{7}$ & $1 / 6$ & $1 / 5$ & $1 / 6$ & $1 / 3$ & $1 / 3$ & $1 / 3$ & 1 & 0.034 & \\
\hline
\end{tabular}

Table 3. The weight allocation table of key affecting factors.

\begin{tabular}{ccc}
\hline Importance number & The name of the key affecting factors & Relative weight \\
\hline 1 & Process system is not perfect & 0.308 \\
3 & Quality management system of new product development project is not perfect & 0.226 \\
4 & The executive ability of quality management organization is insufficient & 0.168 \\
5 & The training scheme for Employees is not reasonable & 0.125 \\
6 & The values of employees deviate from Business goals & 0.082 \\
7 & Procurement quality control is weak & 0.057 \\
\hline
\end{tabular}




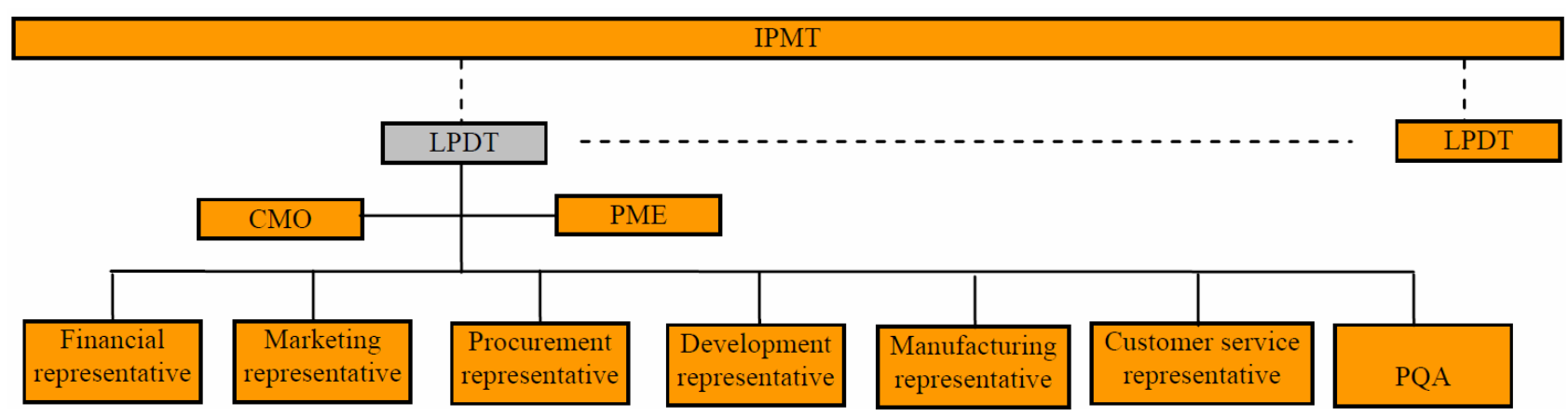

Figure 4. IPMT organization structure chart.

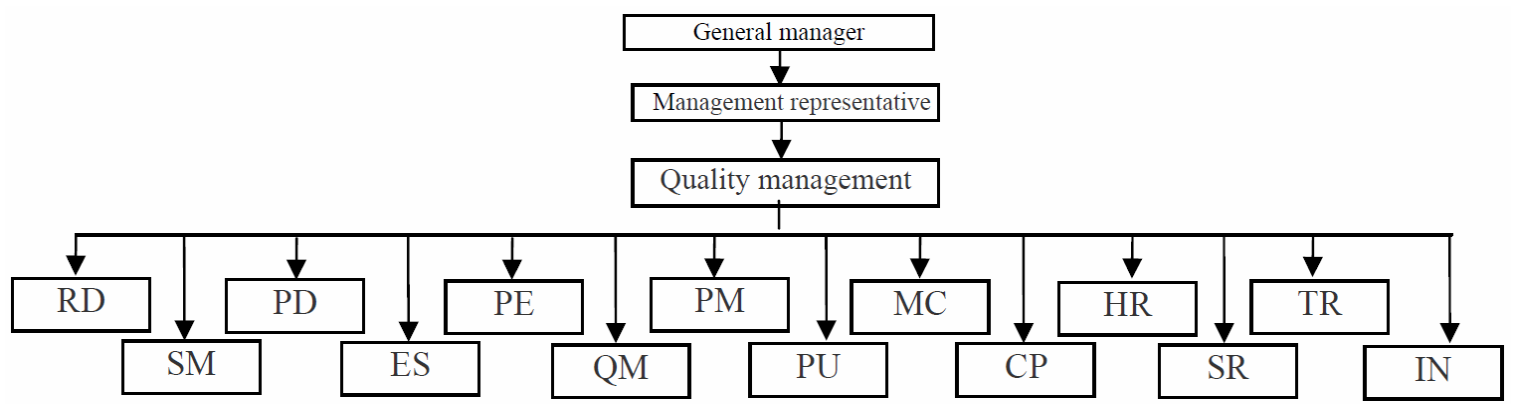

Figure 5. Organizational structure chart of quality management activities of new product development.

Table 4. Function allocation table of quality system elements of W company's new product development.

\begin{tabular}{|c|c|c|c|c|c|c|c|c|c|c|c|c|c|c|c|c|c|}
\hline \multirow{2}{*}{$\begin{array}{c}\text { ISO9001 } \\
\text { ISO9001clause }\end{array}$} & \multirow{2}{*}{ The relevant documents or procedures } & \multirow{2}{*}{ GM } & \multirow{2}{*}{$\mathrm{MR}$} & \multicolumn{4}{|c|}{$\mathrm{VB} / \mathrm{IB}$} & \multicolumn{5}{|c|}{$\mathrm{SC}$} & \multirow{2}{*}{$-\mathrm{CP}$} & \multirow{2}{*}{ HR } & \multirow{2}{*}{ SR } & \multirow{2}{*}{ TR } & \multirow{2}{*}{ IN } \\
\hline & & & & $\mathrm{RD}$ & SM & $\mathrm{PD}$ & $\mathrm{ES}$ & $\mathrm{PE}$ & QM & PM & PU & $\overline{\mathrm{MC}}$ & & & & & \\
\hline 4.1 General requirements & A full set of quality system documents & $\bullet$ & $\bullet$ & $\bullet$ & $\bullet$ & $\bullet$ & $\bullet$ & $\bullet$ & $\bullet$ & $\bullet$ & $\bullet$ & $\bullet$ & $\bullet$ & $\bullet$ & $\bullet$ & $\bullet$ & $\bullet$ \\
\hline & Quality manual & $\bullet$ & $\bullet$ & $\bullet$ & $\bullet$ & $\bullet$ & $\bullet$ & $\bullet$ & $\bullet$ & $\bullet$ & $\bullet$ & $\bullet$ & $\bullet$ & $\bullet$ & $\bullet$ & $\bullet$ & $\bullet$ \\
\hline \multirow[t]{2}{*}{ 4.2 Document requirements } & $\begin{array}{l}\text { Document and material control } \\
\text { procedure }\end{array}$ & ० & ० & $\bullet$ & ० & ० & $\circ$ & ० & $\bullet$ & ० & ○ & $\circ$ & $\bullet$ & ० & $\bullet$ & $\bullet$ & ० \\
\hline & Quality records control procedure & ○ & ○ & $\bullet$ & $\bullet$ & ○ & $\circ$ & ○ & $\bullet$ & $\bullet$ & $\bullet$ & $\bullet$ & ○ & $\bullet$ & $\bullet$ & $\bullet$ & ○ \\
\hline \multirow[t]{2}{*}{ 5.1 Management commitment } & Quality manual & $\bullet$ & $\bullet$ & ○ & ○ & ○ & ० & ○ & $\bullet$ & ○ & $\circ$ & $\circ$ & ○ & o & ○ & ० & ○ \\
\hline & Order review control procedure & $\circ$ & ० & ० & $\bullet$ & ० & $\bullet$ & $\bullet$ & ○ & $\bullet$ & ० & $\circ$ & ० & ० & ० & $\circ$ & ० \\
\hline 5.2 Customer-oriented & $\begin{array}{l}\text { Measurement and analysis of customer } \\
\text { satisfaction control procedure }\end{array}$ & ० & $\circ$ & $\circ$ & ० & ० & $\bullet$ & $\bullet$ & $\circ$ & ० & ० & $\circ$ & $\circ$ & $\circ$ & ० & o & ० \\
\hline 5.3 Quality policy & Quality manual & $\bullet$ & $\bullet$ & $\circ$ & $\circ$ & $\circ$ & $\circ$ & $\circ$ & $\bullet$ & $\circ$ & $\circ$ & $\circ$ & $\circ$ & $\circ$ & $\circ$ & $\circ$ & $\circ$ \\
\hline 5.4 Planning & $\begin{array}{l}\text { Control procedure of quality } \\
\text { management system planning }\end{array}$ & ० & $\bullet$ & ० & $\circ$ & $\circ$ & $\circ$ & ० & $\bullet$ & ० & ० & $\circ$ & ० & ० & ० & ० & ० \\
\hline $\begin{array}{l}5.5 \text { Responsibility, authority } \\
\text { and communication }\end{array}$ & $\begin{array}{l}\text { Internal information communication and } \\
\text { control procedure }\end{array}$ & ○ & $\bullet$ & ० & ० & ० & ० & o & $\circ$ & ० & ० & $\circ$ & $\bullet$ & ० & ० & $\circ$ & ० \\
\hline 5.6 Management review & Management review control procedure & $\bullet$ & $\bullet$ & ○ & $\circ$ & ○ & $\circ$ & $\circ$ & $\circ$ & $\circ$ & ○ & $\circ$ & $\circ$ & $\circ$ & ○ & $\circ$ & $\circ$ \\
\hline 6.1 Resources supply & Quality system documents & $\bullet$ & $\bullet$ & $\circ$ & ○ & ○ & ○ & $\circ$ & $\circ$ & $\circ$ & ○ & $\circ$ & ○ & ○ & ○ & ○ & ○ \\
\hline \multirow{2}{*}{ 6.2 Human resources } & Human resources control procedure & ○ & ० & $\circ$ & ○ & ○ & $\circ$ & ○ & $\circ$ & ० & ○ & $\circ$ & ○ & $\bullet$ & ○ & $\circ$ & $\circ$ \\
\hline & Staff training control procedure & $\circ$ & $\circ$ & $\circ$ & ○ & $\circ$ & ० & $\circ$ & $\circ$ & ० & $\circ$ & $\circ$ & $\circ$ & $\bullet$ & $\circ$ & $\circ$ & $\circ$ \\
\hline 6.3 Infrastructure & $\begin{array}{l}\text { Infrastructure management control } \\
\text { procedure }\end{array}$ & ○ & ○ & $\circ$ & ० & ○ & ० & o & $\circ$ & ० & ० & O & 0 & • & $\circ$ & O & $\bullet$ \\
\hline 6.4 Working environment & Working environment control procedure & ० & ○ & ○ & ○ & ० & ० & $\circ$ & $\circ$ & $\circ$ & $\circ$ & $\circ$ & $\circ$ & $\bullet$ & ० & $\circ$ & $\circ$ \\
\hline $\begin{array}{l}7.1 \text { Planning of product } \\
\text { realization }\end{array}$ & Quality system documents & 0 & 0 & • & 0 & 0 & $\bullet$ & $\bullet$ & $\bullet$ & $\bullet$ & 0 & 0 & 0 & 0 & $\bullet$ & $\bullet$ & 0 \\
\hline
\end{tabular}




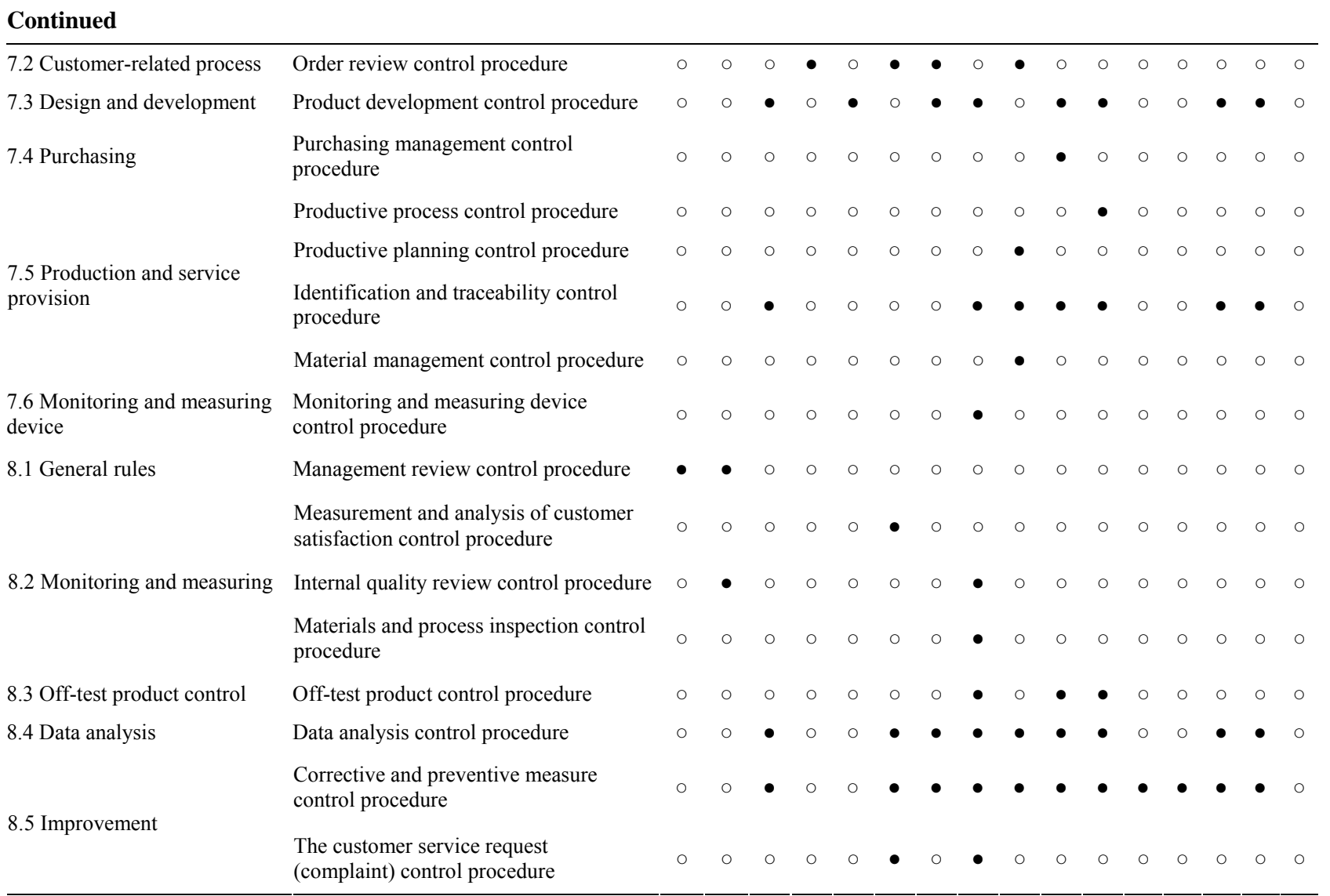

Notes: Sponsor • Co-Organizer $\circ$ GM-general manager MR-management representative.

Table 5. The definition and explain involved in technique review of new product development project.

\begin{tabular}{cc}
\hline Abbreviation & Explain \\
\hline TR & Technique Review \\
DCP & Decision Check Point \\
IPD & Integrated Product Development \\
IPMT & Integrated Product Management Team \\
PDT & Product Development Team \\
SE & System Engineer \\
PQA & Product Quality Assurance \\
LPDT & PDT Leader \\
\hline
\end{tabular}

responding promotion mechanism and incentive mechanism.

\subsubsection{Upgrade Suppliers' Management Level}

W company passes through the following measures to intensify the management of supplier: refer to quality management system of the company's new product development project, develop a detailed examine and verify mechanism and improve the qualified suppliers management standards for the quality and schedule of purchased material.

\subsubsection{Improve Resource Utilization Efficiency}

W company's management ability is relatively poor for basic resources, mainly there is not effective use in the IT tools and not very good to support company business development.

\section{Implement and Effect Analysis of Improvement Scheme in Quality Management within W Company's New Product Development Project}

\subsection{Implement of Improvement Scheme of Quality Management of W Company's New Product Development Project}

W company's 5 measures based on the improvement scheme of new product development project quality include 5 stages (Figure 6), namely concept formation, planning, new product development, validation and product release. TR1 to TR6 is 6 promotion of review process, each review is a sublimation to the last review. Each review process includes four parts: periodical quality objectives decomposition, monitor and measure periodical index, data analysis improvement and summarize and periodical project quality brief report. Four processes keep continuous cycle, promote the continuous upgrade of the ac- 
tivities in quality management of new products.

\subsection{Implement Effect Analysis of the Improvement Scheme of the Quality Management of W Company's New Product Development Project}

\subsubsection{Comparison and Analysis of New Product's Defect Rate}

W company uses Measurement Systems Analysis (MSA) technology to get part of new products' defect data. Then they get the state of a new product's defect discovery and phase defect removal rate using defect introduce-discover matrix method to analysis the obtained data (Table 6).

As a result of the improvement scheme of the quality management of W company's new product development project, a new product's defect situation is lower than target value, phase defect removal rate is higher than lowest requirements.

\subsubsection{Comparison and Analysis of New Product's Failure Rate}

New Product's Failure rate refers to the ratio of the failure numbers of new product in a certain period of time and the ones in the whole statistical period (12 months) (Table 7). After using the improvement scheme of the quality management of new product development project, The number, failure rate of new product dropped significantly, The effect of the improvement scheme of the quality management of new product development project is remarkable when it arrives later period.

\subsubsection{Comparison and Analysis of Customer Satisfaction}

This paper applies customer complaint handling to reflect customer satisfaction of $\mathrm{W}$ company after implementing the improvement program of the quality management of new product development project (statistical period is one year) (Figure 7). After using the improvement scheme,

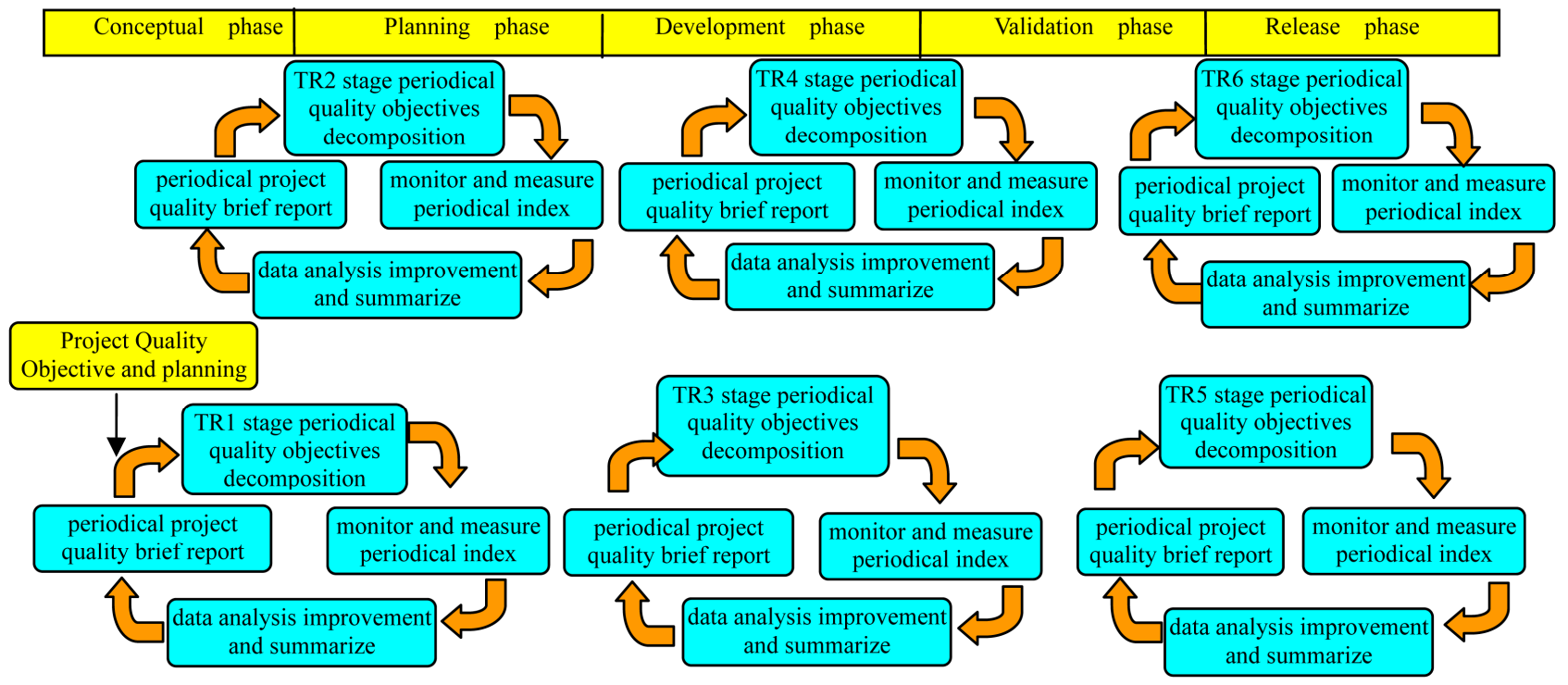

Figure 6. Implement process of the improvement scheme of the quality management of new product development project.

Table 6. Comparison of a new product's defect situation and phase defect removal rate in W company.

\begin{tabular}{cccc}
\hline Total defects & Highest requirement of defect found & Phase defect removal rate & Lowest requirements of phase defect removal rate \\
\hline Actual value & Target value & Actual value & Target value \\
\hline 6 & 30 & $100.00 \%$ & $80.00 \%$ \\
0 & 20 & $100.00 \%$ & $70.00 \%$ \\
5 & 20 & $71.43 \%$ & $70.00 \%$ \\
7 & 35 & $100.00 \%$ & $70.00 \%$ \\
0 & 40 & $100.00 \%$ & $40.00 \%$ \\
38 & 60 & $57.58 \%$ & $40.00 \%$ \\
30 & 33 & $100.00 \%$ & $40.00 \%$ \\
0 & 10 & $100.00 \%$ & $100.00 \%$ \\
0 & 7 & $100.00 \%$ & $100.00 \%$ \\
0 & 5 & $100.00 \%$ & $100.00 \%$ \\
\hline
\end{tabular}


Table 7. The number, failure rate of new product before and after using the improvement scheme.

\begin{tabular}{ccccc}
\hline $\begin{array}{c}\text { Running time of } \\
\text { new product }\end{array}$ & $\begin{array}{c}\text { The number of failure before } \\
\text { using improvement program }\end{array}$ & $\begin{array}{c}\text { The number of failures after } \\
\text { using improvement program }\end{array}$ & $\begin{array}{c}\text { Failure rate before using } \\
\text { improvement program }\end{array}$ & $\begin{array}{c}\text { Failure rate after using } \\
\text { improvement program }\end{array}$ \\
\hline$<1$ month & 18 & 3 & $2.75 \%$ & $0.39 \%$ \\
1 - 3 months & 18 & 19 & $2.75 \%$ & $2.45 \%$ \\
$3-6$ months & 23 & 8 & $3.52 \%$ & $1.03 \%$ \\
6 - 12 months & 38 & 9 & $5.81 \%$ & $1.16 \%$ \\
\hline
\end{tabular}
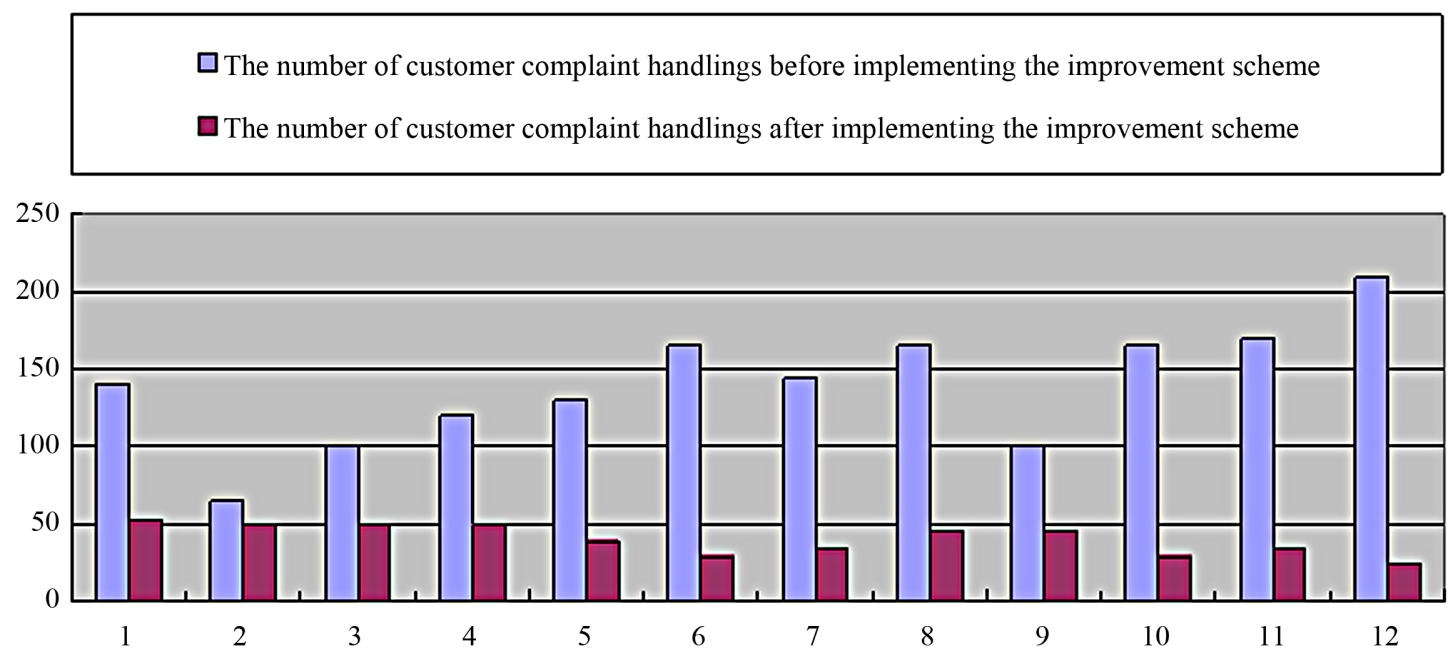

Figure 7. The number of customer complaint handlings before and after implementing the improvement scheme.

the number of customer complaint handling declined more every year. So the improvement scheme has a visible effect on improving product's quality and customer satisfaction.

Through comparison and analysis of defect rate, failure rate of new product and customer satisfaction, we can conclude that the improvement scheme of the quality management of new product development project is reasonable, and it has a remarkable effect. At the same time, it reflects to some extent that key affecting factors model of the quality management of new product development project is in line with the actual situation of $\mathrm{W}$ company.

\section{Conclusion}

Case study for improving quality management of W company's new product development project is carried out. We analyze its current situation, identify existing problems and analysis the cause of existing problems. Based on these foundations, an improvement scheme of quality management of W company's new product development project is put forward, and we monitor the implementation of the improvement scheme and analyze its implement effects. Of course, we just do singleton studies about affecting factors, process and meaning of problems. Whether the improvement scheme of quality management of new product development project has universal applicability remains to be further research and discussion.

\section{Acknowledgements}

Thanks for helpful discussion with Mr. Junqiang Wen, et al.

\section{REFERENCES}

[1] Y. H. Cao, Y. M. Yan and A. C. He, "Application Characteristics of Quality Management System in Enterprise," Coastal Enterprises and Science \& Technology, Vol. 10, No. 6, 2005, pp. 56-60.

[2] M. H. Liu, "The New Development Tendency of Total Quality Management," Liaoning Economy, Vol. 25, No. 8, 2006, pp. 83-84.

[3] K. Hale, "Measuring Organizational Effectiveness and Business Performance in Firms Implementing Total Quality Management," International Journal of Manufacturing Technology and Management, Vol. 8, No. 4, 2006, pp. 355-378. doi:10.1504/IJMTM.2006.009244

[4] G. P. Laszlo, "Project Management: A Quality Management Approach," TQM Magazine, Vol. 3, No. 3, 2003, pp. 157-160.

[5] D. G. Hubbard, "Total Quality Project Management," Proceedings of the Project Management Institute Annual Seminar Symposium, Dallas, 1991, pp. 260-264.

[6] J. Chen, G. Xiang and B. W. Gui, "R \& D Project Management," China Machine Press, Beijing, 2004, pp. 15-19.

[7] C. J. Chen, “Apply Project Quality Management in the Process of New Product Development," Law and Economy, Vol. 18, No. 11, 2009, pp. 58-62. 
[8] Y. S. Peng, "Causal Analysis in the Social Science," Social Science Research, Vol. 26, No. 11, 2011, pp. 14-18.

[9] X. Deng, J. M. Li and H. J. Zeng, "Analytic Hierarchy Process Weight Calculate Method Analysis and Its Application Research," Mathematics in Practice and Theory, Vol. 42, No. 7, 2012, pp. 64-67.

[10] A. H. He, "Study on the Decision-Making of Coal Industry Technology Development Based on AHP," Ad- vanced Materials Research, Vol. 41, No. 4, 2011, pp. 111-114.

doi:10.4028/www.scientific.net/AMR.204-210.911

[11] S.-H. Li, "Research on Evaluation System of New Energy Vehicles Based on AHP," Applied Mechanics and Materials, Vol. 42, No. 3, 2012, pp. 321-325. 